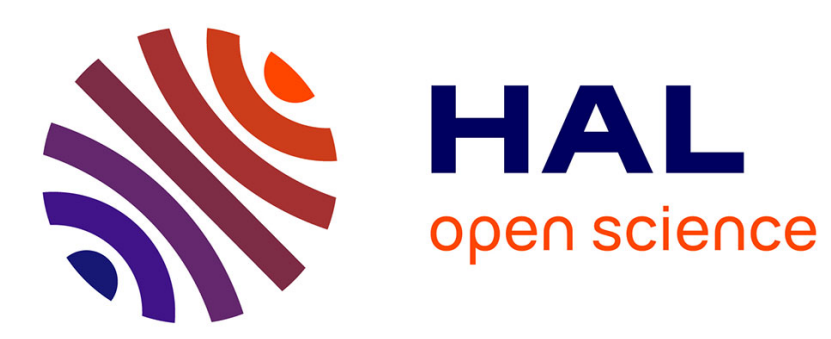

\title{
Quality identification methodology applied to wall-elements based on modal analysis
}

Mariusz Zóltowski, Tomasz Kalaczynski, Ronald Martinod

\section{To cite this version:}

Mariusz Zóltowski, Tomasz Kalaczynski, Ronald Martinod. Quality identification methodology applied to wall-elements based on modal analysis. Multidiscipline Modeling in Materials and Structures, 2015, 11 (4), pp.507-516. 10.1108/MMMS-06-2015-0030 . hal-02182057

\section{HAL Id: hal-02182057 \\ https://hal.univ-lorraine.fr/hal-02182057}

Submitted on 16 Jul 2019

HAL is a multi-disciplinary open access archive for the deposit and dissemination of scientific research documents, whether they are published or not. The documents may come from teaching and research institutions in France or abroad, or from public or private research centers.
L'archive ouverte pluridisciplinaire HAL, est destinée au dépôt et à la diffusion de documents scientifiques de niveau recherche, publiés ou non, émanant des établissements d'enseignement et de recherche français ou étrangers, des laboratoires publics ou privés. 


\title{
Quality Identification Methodology Applied to Wall-elements based on Modal Analysis
}

\author{
Mariusz ŻÓŁTOWSKI \\ Uniwersytet Technologiczno-Przyrodniczy w Bydgoszczy \\ Wydział Inżynierii Mechanicznej \\ Ul. S. Kaliskiego 7, 85-796, Bydgoszcz, Poland \\ (052) 3408240 \\ mariusz.zoltowski@utp.edu.pl \\ Tomasz KAŁACZYŃSKI \\ Uniwersytet Technologiczno-Przyrodniczy w Bydgoszczy \\ Wydział Inżynierii Mechanicznej \\ Al. Prof. Kaliskiego 7, 85-796, Bydgoszcz, Poland \\ (052) 3408240 \\ kalaczynskit@utp.edu.pl \\ Ronald M. MARTINOD \\ Universidad EAFIT \\ Mechanical Engineering Department \\ Cra. $49 \mathrm{~N}^{\circ} 7$ Sur 50, Medellín, Colombia \\ (574) 2619500 \\ rmartino@eafit.edu.co
}

\begin{abstract}
The recommendation of structural norms, as PN-B-03002, shows a need to control the production quality of wall-elements; the quality control demands suitable guidelines to fit the requirements of the current mass-production of the wall-elements, then, the structural standard recognizes the need of improving the methods to identify the real elements quality. The presented work is developed with an approach that applies advanced calculating techniques used for the structural analysis in civil engineering focused on the technical state assessment of wall-elements. The paper also proposes a diagnostic methodology that can be added to the current regulations and standards based on experimental modal analysis techniques.
\end{abstract}

\section{Keywords}

Coherence function, experimental modal analysis, manufacturing quality, stabilization diagram, wall-element.

\section{INTRODUCTION}

Existing civil constructions and masonry structures, such as: (i) buildings; (ii) chimneys; (iii) high poles; (iv) roofs; and (v) machines foundation; are subject to dynamic effects caused by: the environment -wind, earthquakes and sea waves-, and vibration or trembling events -explosions, machines work, 
railways and road movement-. Trembling in buildings decreases living comfort, and has an influence on: (i) the people working there; and (ii) threatening the safety level of the construction -the trembling events cause dynamic load and can generate catastrophic destruction- [1].

The need of building civil constructions with dynamic fail-safe effects has been identified. To identify the quality of the wall-elements (basic bricks, breeze blocks, light bricks, repressed bricks, double bricks, insulating bricks, featheredged bricks, etc.) there is a technical effort to project constructions and to improve the safety and stability of the civil constructions [2]. The structural engineering then recognizes the need of improving the methods to determine the real quality of wall-elements used in constructions, by means of the assessment of wall safety coefficients defined by the structural norm (PN-B03002). This norm requires establishing the partial coefficients of wallelements, called safety coefficients, to classify the category of the works that are performed on buildings. Currently in a line production, the wall-elements quality control is made manually based on visual inspection; this method is subjective and do not evaluate the technical state of the element.

In this paper, a technique for the assessment of the damage level of wallelements has been adopted, based on non-intrusive tests through the measurement of a set of signals, using the Experimental Modal Analysis (EMA)-based techniques. EMA is applied directly to wall-elements tests based on measuring the dynamic system excitation and response according to the classical modal analysis theory [3]. EMA has been widely documented [4-6], and the modal properties of dynamic systems can be identified using standard identification methods in the time domain $[7,8]$; the following methodology is proposed for this study:

(i) apply an excitation to the wall-element with an impact hammer, shaker, etc., and the excitation/response signals are recorded by means of a data acquisition system;

(ii) process the signals recorded though EMA-based techniques; the modal properties are identified by using two different methods:

- the Least-Square Complex Exponential (LSCE) method to calculate the Stabilization Diagram (SD) [9],

- the Coherence function $\left(\operatorname{Coh}_{i j}\right)$; and

(iii) determine an estimator that synthesize the SD and $\left(C o h_{i j}\right)$ information, and in this way, the estimator identifies the technical state of the wallelement; and

(iv) normalize the estimator value to get an index into the scale defined by the structural norm, e.g. the safety coefficients defined by PN-B-03002.

The proposed inspection methodology corresponds to assessment models that combine the numerical and symptomatic models to evaluate the critical levels; these have been previously used by the authors in technical systems of railways and structure field [10-12]. The developed inspection methodology is feasible to be applied to the wall-elements mass-production, since it uses sensors (force sensor, accelerometers) of easy installation and operation, while they record reliable signals. The proposed approach can be used for better understanding the behaviour of constructions, which allows optimizing the projection and assessment of critical states. 


\section{BACKGROUND}

EMA is used to determine the behaviour of the wall-elements under given dynamic effects condition $[13,14]$. Consider a squared matrix $[A]$ of real numbers having a size of $n \times n$, eigenvalues $\lambda_{r}$, and corresponding eigenvectors $\{\phi\}_{r}$ with $(r=1,2, \ldots, n)$; the $\{\phi\}_{r}$ family consists of independent vectors. The matrix of $\lambda_{r}$ can be expressed in the form $[\Lambda]=$ $\operatorname{diag}\left[\lambda_{1}, \lambda_{2}, \ldots, \lambda_{n}\right]$, and the matrix of $\{\phi\}_{r}$ as $[\Psi]=$ $\operatorname{diag}\left[\{\phi\}_{1},\{\phi\}_{2}, \ldots,\{\phi\}_{n}\right]$. The decomposition of eigenvectors produces the equation $[A]=[\Psi][\Lambda][\Psi]^{-1}[5]$.

The equation shows that $[A]$ may be expressed as a diagonal matrix in the form $[\Lambda]=[\Psi]^{-1}[A][\Psi]$. For all range $[A]$, the only solution satisfying that $\lambda_{r}$ and its corresponding non-null $\{\phi\}_{r}$ exist is when $\left([A]-\lambda_{r}[I]\right)\{\phi\}_{r}=\{0\}$. This determinant can be expanded, obtaining a polynomial $n$ for $\lambda$. The polynomial's roots are $\lambda_{r}$ of $[A] . \lambda_{r}=0$ indicates that the vibration mode is a rigid body fixed to the ground. If $\lambda_{i}=\lambda_{r}$, it means that there are identical modal shapes, a phenomenon that occurs frequently in symmetrical structures.

\subsection{EMA-LSCE method}

EMA associated to LSCE method assesses the global modal parameters: natural frequency $\Omega\left(\sqrt{\lambda_{r}}\right.$ is equivalent to $\Omega$ ) and damping ratio $\xi$. LSCE method determines the relation between the Impulse Response Function (IRF) in a Multiple Degrees of Freedom (MDoF) system. The IRF can be derived from the inverse Fourier Transform (FT) for a Frequency Response Function (FRF) through the Power Spectral Density (PSD), the Random Decrement (RD) process, the inverse Laplace transform or other methods [15].

The inverse Laplace transform of the transfer function of an MDoF system is the IRF, $h_{k}$. This gives as a result a series of equally spaced time intervals $k \Delta(k=0,1, \ldots 2 n)$, and then it is possible to express IRF as [5]

where

$$
h_{k}=\sum_{r=1}^{2 n}{ }_{r} A_{i j} z_{r}^{k} ; \text { with } z_{r}^{k}=\mathrm{e}^{s_{r} k \Delta} \text {, }
$$

$$
{ }_{r} A_{i j}=\phi_{i r} \phi_{j r}
$$

This expression is the product of the $i$ th and $j$ th elements in the modal shape $r$ th, $\{\phi\}_{r}$, and named as modal constant. The values in the series belong to the real numbers even if the residues and the roots $s_{r}$ are complex values. It is possible to demonstrate that all imaginary parts will cancel each other because of the complex conjugates for both expressions: ${ }_{r} A_{i j}$ and $s_{r}$. The next step is to estimate the roots and the residues for the sampled data. This solution is aided by the conjugate of the roots $s_{r}$, therefore, $z_{r}$. Mathematically, this means that $z_{r}$ are the roots of a polynomial with only real coefficients [5]

or

$$
\beta_{0}+\beta_{1} z_{r}+\beta_{2} z_{r}^{2}+\cdots+\beta_{2 n} z_{r}^{n 2}=0
$$

$$
\sum_{k=0}^{2 n} \beta_{k} h_{k}=\sum_{r=1}^{2 n}{ }_{r} A_{i j} \sum_{k=0}^{2 n} \beta_{k} z_{r}^{k} .
$$


This equation is known as the Prony equation. The coefficients can be estimated by the IRF values. An Auto-Regressive (AR) model is constructed by the relation between poles and residues, which are processed to perform the estimation of the poles given, as they provide information about the quality of the data and the computational resources requirements (a model of higher order imply a greater processing cost) [16]. The AR model solution allows to define a polynomial in whose roots the complex roots of the system are present; having established the roots (equivalent to the natural frequencies $\Omega$ and the damping rates $\xi$ ), the residues can be derived through the AR model and then the modal shapes $\{\phi\}_{r}$ can be obtained [5].

With the calculation of the system poles, it is possible to build the SD, which allows to graphically represent the poles of a system when it is excited in one point -reference- and the measurements are made in another one -responses[8]. It can be seen that the estimated poles for certain frequencies create stable vertical lines. The vertical lines are generated in the characteristic frequencies of the system; then, it is possible to affirm that the pole identifies modal parameters if [7]: (i) the pole is stable at the concerned frequency; and (ii) the pole frequency appears in the characteristic frequency. An adequate interpretation of the SD allows the correct identification of the poles of the system. The SD exposes the characteristics of the poles, which are presented in code with alphanumeric characters: stable pole (s), stable vector and modal vector frequencies $(\mathrm{v})$, stable vibration and softening frequencies $(\mathrm{d})$, stable vibration frequency (f), and unstable pole (o), (see Figure 1). Once the poles have been selected it is possible to estimate the vibration shape [17].

\subsection{EMA-Coh function}

$\mathrm{Coh}_{i j}$ function finds the estimation of the magnitude squared coherence of an excitation signal, $i(f)$, and response signal, $j(f)$, in the frequency domain, using Welch's averaged, modified periodogram method. The magnitude squared coherence is a function of frequency domain with values a range of values $[0,1]$ that indicates how well $i(f)$ corresponds to $j(f)$. The coherence is a function of the power spectral density $P_{i i}, P_{j j}$ of $i(f)$ and $j(f)$ and the cross power spectral density $P_{i j}$, then $\operatorname{Coh}_{i j}(f)=\frac{\left|P_{i j}(f)\right|}{P_{i i}(f) \cdot P_{j j}(f)}$

$\operatorname{Coh}_{i j}(f)$ is calculated whit a periodic Hamming window of length to obtain eight equal sections of $i(f)$ and $j(f)$, and the value to obtain and 50\% overlap.

\section{DESCRIPTION OF THE CASE OF STUDY}

The research has been conducted to two identical set of wall-elements, the proprieties of all the bricks were similar: (i) length, $250 \mathrm{~mm}$; (ii) width, $120 \mathrm{~mm}$; (iii) height, $65 \mathrm{~mm}$; and (iv) mass, $3.5 \mathrm{~kg}$; provided by a recognized brick producer in Bydgoszcz (Poland).

One set has a nonconformity manufacturing and will be called fault wallelements, $W_{F}$. The second set has approved quality, representing the nominal structural behaviour, i.e. the second set shows the reference values, $W_{R}$. Each 
wall-element was tested at the principal axes: (i) $x$, longitudinal; (ii) $y$, lateral; and (iii) $z$, vertical.

The measurement point is important as it has influence on the results of modal investigations $[18,19]$. The accelerometers should be fixed in such way that they will not influence the arrangements performance [20]; as well as they should be fixed in characteristic places of the wall-element. The wall-elements must be fixed to a correct assemblage according to the input perturbations. Perturbations must be performed on object in normal operation; during experimental realization, the mounting must have the correct boundary conditions to get realistic DoF [21]. The excitation-response performance has been recorded in a DAQ system by means of a set of single-axial piezoelectric accelerometers, PCB-352C68-ICP model. The signals in the time domain from DAQ system were exported to a real-time signal software package.

\section{PROCESSING AND ANALYSIS RESULTS}

The obtained results have been analysed with an algorithm written in two programing codes based on Matlab programing language: (i) the Virtual In Operation Modal Analysis -Vioma- [22]; and (ii) the Computer System of Identification Investigations -SIBI- [23]. All datasets recorded are available from the authors of this paper, as an example, the data recorded from $W_{F}$ and $W_{R}$ are shown in Figure 1 and Figure 2.

Figure 1. Stabilization Diagam (SD) of recorded signals

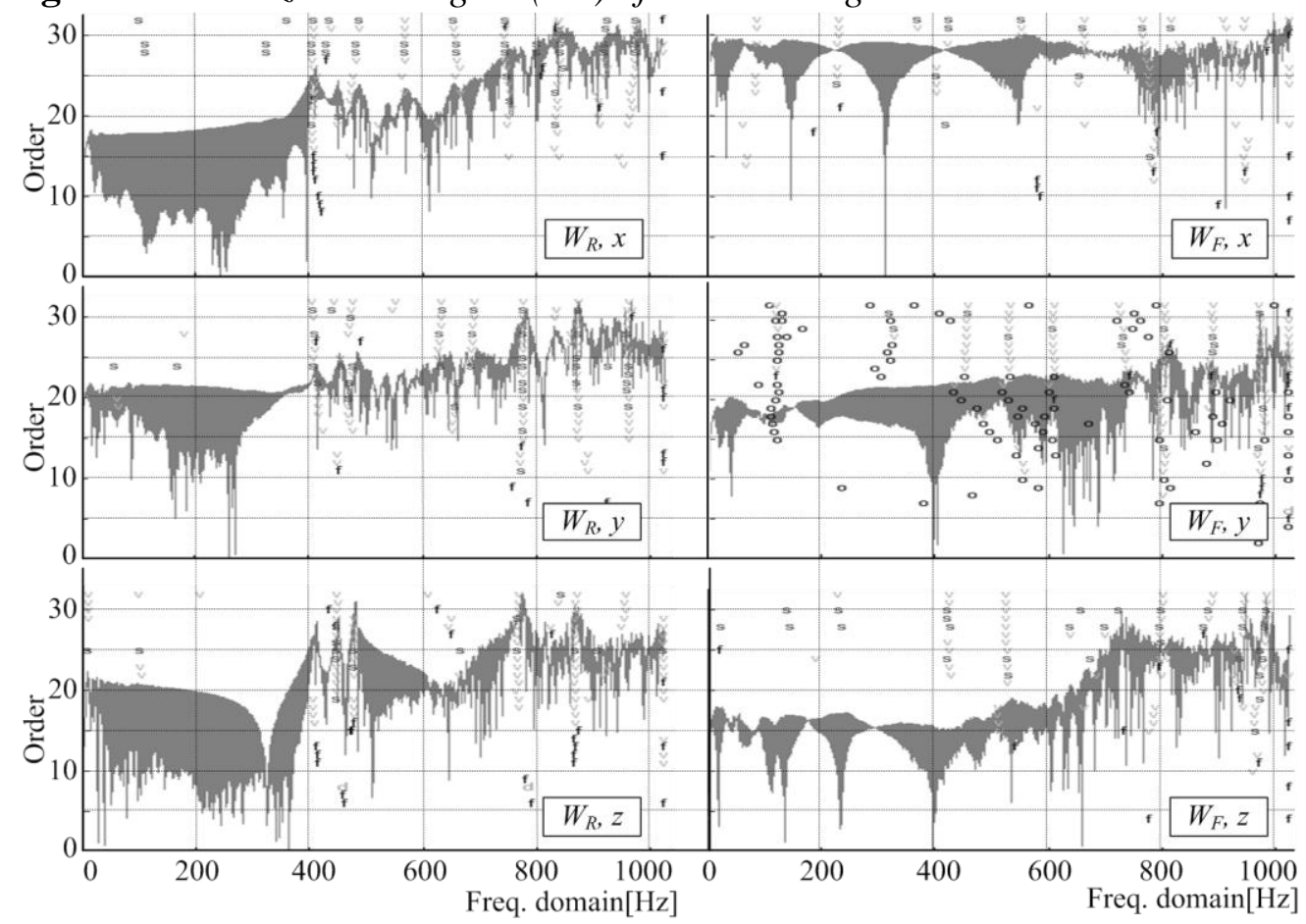


Figure 2. $\operatorname{Coh}_{i j}(f)$ function of recorded signals

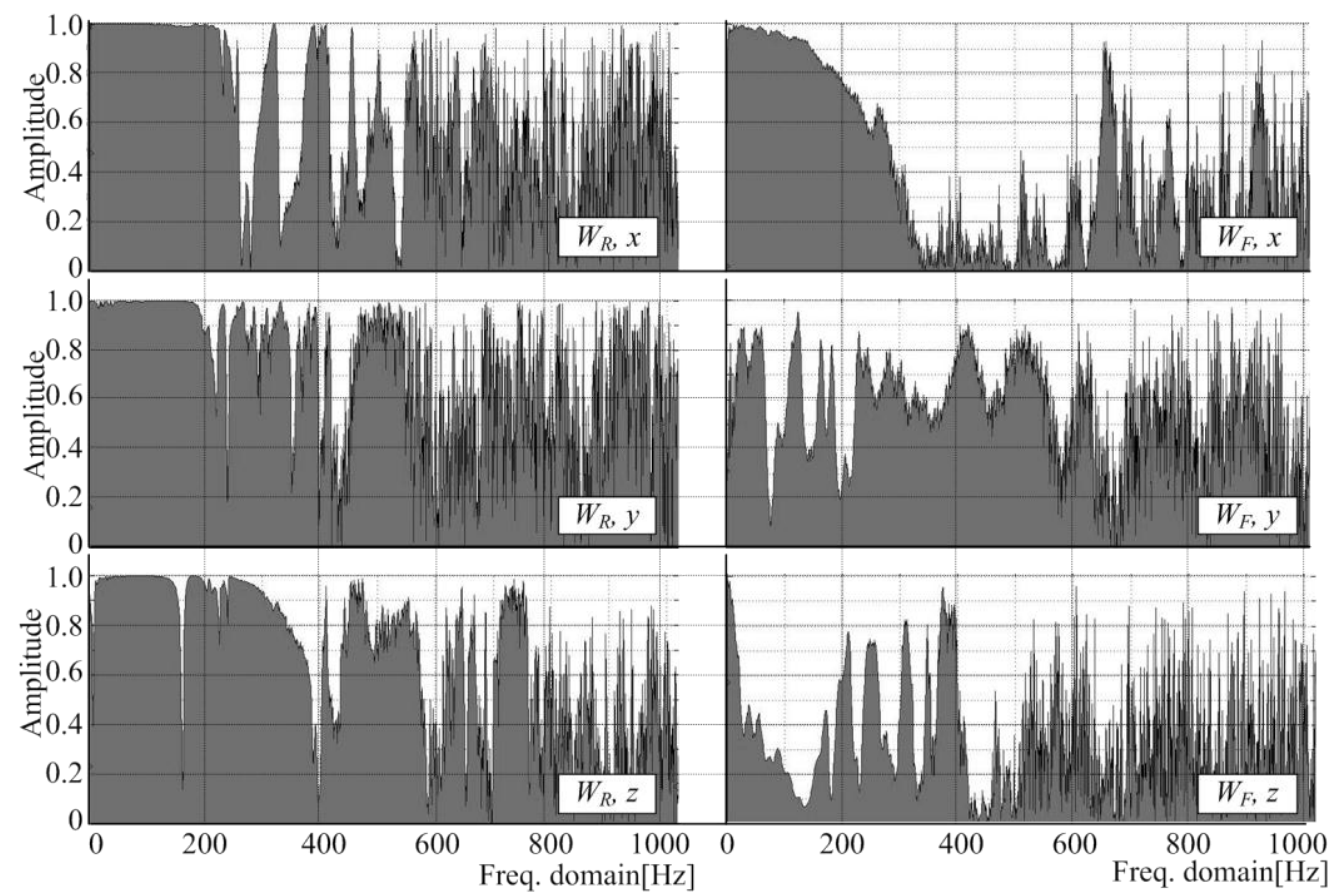

An estimator value must be defined to synthetize the SD and $C o h_{i j}$ information and identify the technical state of the wall-elements. The criterion for defining the estimator is the computational resources requirements (low processing cost), then the selected estimator is the area under the SD and $C o h_{i j}$ fuctions, $\left\{S D, \operatorname{Coh}_{i j}\right\}_{(\text {Area })}$, Figure 3 shows the estimator of recorded signals, and shows a clear difference to identify the quality of the wall-elements, due the difference of reference relative the fault wall-elements is $88.3 \%$ and $82.7 \%$ to

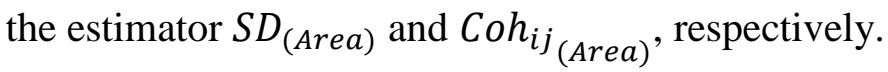

Figure 3. $S D$ and $\operatorname{Coh}_{i j}(f)$ estimator of recorded signals

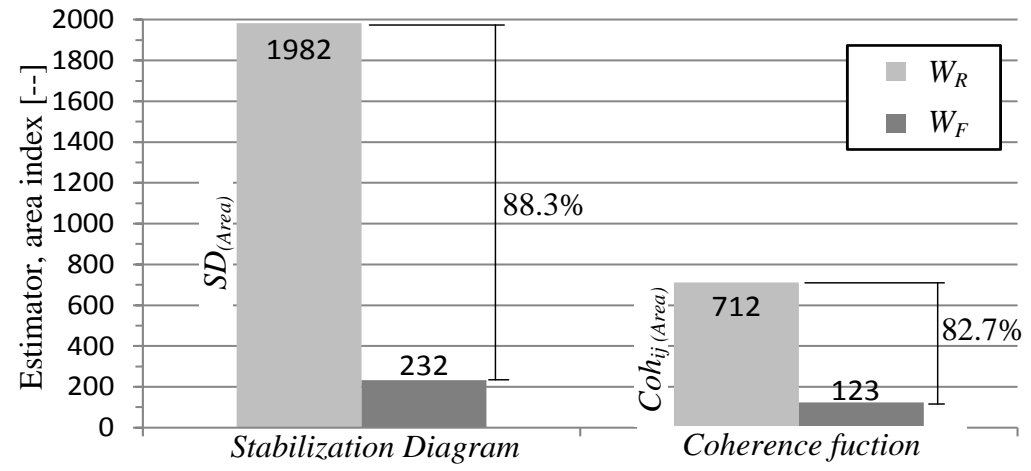

\section{CONCLUTIONS}

The introduced results of this investigation show the existing possibility of distinguishing changes in material properties. The investigation confirmed that the application is useful as it makes possible to create $\mathrm{SD}$ and $\operatorname{Coh}_{i j}(f)$ 
functions. The data obtained from these diagrams and functions allows assessing the state of materials by comparing their fitness.

From the obtained results, the following statement can be made:

(i) for a full fit wall-element, $W_{R}$, a stable pole can be generated in direction $x$ at a stabilization level of $420 \mathrm{~Hz}$. In case of a fault wall-element, $W_{F}$, it is not possible to generate a stable pole in the SD. The situation is the same when comparing $x$ and $y$ SD. This means that for $W_{R}$, a stable pole can be generated in the $y$ axis at a stabilization level of $790 \mathrm{~Hz}$; in case of a $W_{F}$, it is not possible to generate a stable pole in the SD; and

(ii) for $z$ axis, it was not possible to generate stabilization diagrams neither for good or damaged materials. The studies performed in this axis did not provide any answers and, therefore, further investigation should only be performed on the first to axis, $x$ and $y$.

The estimator value $\left\{S D, C o h_{i j}\right\}_{(\text {Area })}$ represents an appropriate index to identify the technical state of the wall-elements and to define the quality control process in a line production of wall-elements factory. The $\left\{S D, \operatorname{Coh}_{i j}\right\}_{(\text {Area })}$ can be directly normalized to get an index into the scale defined by a national structural standard.

The proposed methodology is useful whereas the data logging allows getting information in terms of commercial operation, avoiding measurements that require downtime for the system inspection.

The paper opens to different research fields, the elements can be considered for future studies, e.g. to establish the estimator value $\left\{S D, \operatorname{Coh}_{i j}\right\}_{(\text {Area })}$ limit to a particular wall-element and particular national structural standard.

\section{ACKNOWLEDGMENTS}

The work was executed in frames of POIG nr. WND-POIG.01.03.01-00212/09 (Poland), and COLCIENCIAS (Colombia).

\section{REFERENCES}

Giergiel, J., 2000. Mechanical trembling. AGH, Kraków.

Kaczmarek, J. 1993. Basis of theory of trembling and dynamics of machines. Higher Morska Szkoła, Szczecin.

Hanson, D., Randall, R. B., Antoni, J., and et al. 2007. Cyclostationarity and the Cepstrum for Operational Modal Analysis of MIMO Systems - Part I: Modal Parameter Identification, Mech. Syst. and Signal Processing, 21, 6, 2441-2458. DOI= 10.1016/j.ymssp.2006.11.008.

Ewins, D. J., 2000, Modal Testing: Theory, Practice and Application (Mechanical Engineering Research Studies: Engineering Dynamics Series), Research Studies Press, Second Ed, Hertfordshire, UK.

He, J., Fu, and Z. 2001. Modal Analysis. Butterworth-Heinemann, UK.

Genta, G. 2009. Vibration Dynamics and Control. Springer Science Business, Italy.

Uhl, T., and Kurowski, P. 2002, Vioma User's Guide. University of Mining and Metallurgy in Kraków Press, Kraków, Poland.

Uhl, T. 2006. The Inverse Identification Problem and its Technical Application. Springer-Verlag, Heidelberg, Germany. 
Giergiel, J., and Uhl, T. 1990. Identification of mechanical arrangements. PWN, Warsaw.

Żółtowski, M. and Orłowicz, R. 2005. Chosen questions of acoustic isolation of wood ceilings. Ogólne building, ZN ATR, 367-374.

Żółtowski, M. 2005. Identification of the vibration threats of building objects, ZN ATR: $375-382$.

Martinod, R. M., Betancur, G. R., and Castañeda, L. F. 2012. Evaluating damping elements for two-stage suspension vehicles, Ingenieria. e Investigacion, 32, 1 (June 2012), 11-17.

Cempel, C. 1989. Practical Wibroakustyka. PWN, Warsaw.

Tylicki, H. 1999. Optimization of process of forecasting of technical state of motor vehicles. Qualifies for professorship trial of No. 86, ATR, Bydgoszcz.

Uhl, T., and Lisowski, W. 1996. Practical problems of analysis of modal construction. CCATIE, Kraków.

Uhl, T. 1997. By computer helped identification of models of mechanical constructions. WNT, Warszawa.

Chauhan, S., Hansen, M. H., and Tcherniak, D. 2009. Application of Operational Modal Analysis and Blind Source Separation/Independent Component Analysis Techniques to Wind Turbines. Brüel \& Kjær Sound \& Vibration Measurement, Denmark.

Bendat, J. S., and Piersol, A. G. 1996. Method of analysis and measurement of random signals. PWN, Warsaw.

Eykhoff, P. 1980. Identification in dynamic arrangements. BNInż, Warsaw.

Morrison, F. 1996. Art of modelling of dynamic arrangements. WNT, Warsaw.

Carpenter's, R. 1993. Dynamic diagnostics in building. Building review. Nr. 1.

Kurowski, P. 2001. Identification of Modal Models for Mechanical Constructions on the Basis of Exploitation Measurements. Doctoral Thesis, AGH, Kraków.

Martinod, R. M., Betancur, G. R., Castañeda, L. F., and et al. 2013. Estimation of combustion engine technical state by multidimensional analysis using SVD method. Int J Vehicle Systems Modelling and Testing, 8, 2 (June 2013), 105-118. DOI= 10.1504/IJVSMT.2013.054476. 